\title{
SÊNECA E A TERAPIA DE CURA DAS AFECÇÕES DA ALMA
}

\section{Mariana Monteiro Condé}

\begin{abstract}
RESUMO
Tendo em vista o caráter trágico da condição humana, do qual a finitude e os infortúnios são os traços mais marcantes, Sêneca buscará formular, em sua filosofia moral, uma estratégia capaz de lidar com nossos estados de alma de perturbação. Neste sentido, o objetivo deste artigo é o de examinar em que consiste a terapia senequiana de cura das afecções da alma humana, o que se busca levar a termo ao traçar a relação existente entre alguns aspectos de sua antropologia e da escala de valores estoica. Ora, o que se argumenta aqui é que a terapia em questão consiste numa estratégia de re-valoração, amparada, sobretudo, na busca pelo sentido dos fenômenos e, também, no hábito da contínua meditação.
\end{abstract}

Palavras-chave: Sêneca. Antropologia e axiologia estoicas. Terapia.

\begin{abstract}
Having in mind the tragic character of the human condition, of which finitude and misfortunes are the most remarkable traits, Seneca will make use, in his moral philosophy, of a strategy that is able to deal with our states of soul named states of perturbation. This being said, the objective of this paper is to examine in what does the Senequean therapy of cure of the affections of the human soul, what will be attempted by drawing the existent relation between some aspects of his anthropology and the Stoic scale of values. What is at stake here is that the aforementioned therapy consists in a strategy of re-valuing, supported overall in the search for the meaning of the phenomena - and also in the habit of continuous meditation.
\end{abstract}

Keywords: Seneca. Stoic anthropology and axiology. Therapy.

\section{Introdução}

O objetivo deste estudo é tratar da problemática relativa à therapeia das afecções da alma nas Epistulae Morales, de Sêneca, a partir de duas perspectivas. Num primeiro momento, o que se busca é explicitar de que modo o caráter trágico inerente à condição humana pode estar relacionado à

\footnotetext{
${ }^{1}$ Professora do Dom Pedro II e doutora em filosofia pela UFMG.

E-mail: nanaconde01@hotmail.com. ORCID: 0000-0002-3027-2344.
} 
escala de valores estoica, constituída pelas categorias de bem, mal e indiferentes. Em outras palavras, se é trágica a condição do ser humano no mundo, faz-se necessária uma terapêutica de re-valoração, ou de ressignificação daquilo que costuma causar perturbação nos seres humanos, haja vista que somente assim seria possível traçar um caminho para se atingir a tranquillitas animi. Tornada explícita essa relação entre antropologia e axiologia na filosofia estoica de Sêneca, buscaremos compreender em que consiste a estratégia esboçada por nosso autor para que possamos transformar o nosso modo de conferir valor a tudo o que nos circunda. Propomo-nos, neste segundo momento, a examinar a hipótese de que a terapêutica senequiana consiste numa tentativa de re-valoração ancorada numa estratégia de via dupla. Por um lado, Sêneca recorre a um procedimento a que chamaríamos de estritamente racional - como, por exemplo, a tentativa de definição e análise das causas de temor; por outro, aborda a aplicação de exercícios repetitivos e disciplinadores, tais como os variados treinamentos diários e os exames de consciência, sempre no intuito de cultivar um ânimo forte. Para isso, Sêneca se vale tanto da tentativa de definir certos conceitos; quanto da utilização de exemplos, metáforas e exortações as mais variadas, a fim de evidenciar que aqueles conceitos, referidos como causas de males terríveis, nada mais constituem que indiferentes de um ponto de vista moral. Trata-se, ao que parece, de um problema de interpretação, e é o que doravante buscaremos explicitar. Por fim, poder-se-ia defender, ainda, a ideia de que superar as adversidades inerentes à condição humana constituiria tarefa de grande valor moral, na medida em que uma tal disposição poderia contribuir para o fortalecimento do eu.

\section{A morte como principal causa de temor e angústia para os seres hu- manos}

Trabalho de maior envergadura teria de ser empreendido a fim de ilustrar a multifacetada figura que faz Sêneca da condição humana. Entretanto, não seria enganoso supor que figuram entre os traços mais marcantes de sua antropologia os temas da morte e do sofrimento - ambos condicionantes do modo humano de estar no mundo. Os seres humanos se definem, e 
também se constituem, sobretudo, pela relação que se estabelece entre seu universo interior e o mundo que os circunda - ambos mediados pelo tempo - e, ao penetrar nesta consciência que adquirem de si mesmos, postulam os problemas da inevitabilidade do sofrimento e da morte, ambos eventos que terão necessariamente de advir e, assim, tocar de perto a todos os seres humanos, configurando assim o viés trágico inerente à condição humana. ${ }^{2}$

Não obstante tomar estes condicionantes como dados fundamentais da vida ética humana, Sêneca faz questão de enfatizar que não os compreende como motivos legítimos e suficientes para que o indivíduo viva atemorizado diante de tudo e de todos. Ora, cabe-nos, ao contrário, procurar compreender que alegrias e sofrimentos estão entretecidos em nosso destino (Ep. CVII 8-10). Neste sentido, a resposta senequiana a uma perspectiva que poderia ser tomada por muitos como pessimista, é das mais positivas, e busca amparar-se, em grande medida, num método de preparação que visa a superação de eventos tidos como adversidades, por meio de sua re-valoração.

Pois bem, a tendência de Sêneca, a fim de argumentar que a existência de adversidades na vida humana não constitui um mal, será a de apresentá-las ao leitor através de uma nova perspectiva: as dificuldades com as quais nos deparamos pela vida afora seriam, antes de tudo, indiferentes do ponto de vista do que realmente importa no âmbito moral, que é a virtude. De fato, uma vez delimitados os âmbitos do que constitui a ação, e do que constitui o modo como a executamos, parece evidente que é nossa disposição que configura a virtude, segundo os critérios estabelecidos pelo estoicismo. Neste sentido, o fato de enfrentarmos uma adversidade seria indiferente - mas não o modo como o faremos.

\footnotetext{
${ }^{2}$ A respeito das noções de vida e morte como constituindo um e mesmo processo, Sêneca cunha uma imagem, a qual pode ser encontrada no sexto passo da epístola XII: “"É penoso', dizes, 'ter a morte diante dos olhos'. Em primeiro lugar, esta deve estar diante dos olhos tanto de um velho quanto de um jovem (pois não somos convocados conforme um censo); em seguida, ninguém é tão excessivamente velho que não espere um dia. Ora, um dia é um degrau da vida. Toda existência consta de partes e tem círculos maiores que circundam menores: há um que abrange e cinge todos (este se estende do nascimento até o dia derradeiro); há outro que exclui os anos da adolescência; há o que restringe toda meninice a seu âmbito; em seguida, há por si o ano, contendo todos os tempos, pela multiplicação dos quais a vida é composta; o mês, rodeado por um círculo mais estreito; o dia, que tem um giro estreitíssimo, porém, este vem do início ao fim, do nascente ao poente." Esta, assim como as seguintes traduções do latim para o português de trechos das Epistulae Morales que se encontram no corpo do texto são de nossa autoria. Exceções, quando houver, serão expressamente indicadas.
} 
Assim, munidos de uma tal convicção, a perspectiva de nossa própria morte ou da de nossos familiares - perspectivas estas aterradoras para a maior parte dos seres humanos - pode adquirir nuanças mais suaves, tornando-se, assim, mais aceitável. A vida, aqui, não representa o mais importante, haja vista que constitui apenas um indiferente preferível ou, ainda, um indiferente digno de ser selecionado, diante de seu contrário, a morte. Conforme esboçado acima, o que há de importar realmente, do ponto de vista ético, é o modo como a vivemos e, ainda, o modo como enfrentaremos a morte, termo desta mesma vida. Mas o que assistimos a todo o momento e para onde quer que nosso olhar se detenha - salvo raras exceções -, é a incompreensão e/ ou a revolta diante de tais fenômenos. Sêneca, perspicaz observador que era, às reações humanas diante de tais questões não estava alheio e, tendo sempre se mostrado preocupado com problemas de caráter existencial, fez da temática da morte uma constante de sua filosofia. No passo abaixo, Sêneca justifica o estudo do referido tema:

E se desse modo a morte é um indiferente, não é, apesar disso, daqueles que se pode com facilidade negligenciar. Com duros exercícios deve-se engrandecer a alma, a fim de que veja a aproximação da morte e possa superá-la. Deve ser desprezada a morte mais do que estamos acostumados a fazer. ${ }^{3}$

Dois parecem ser os principais motivos pelos quais a morte se configura como uma das maiores causas de temor e perturbação humanas. O primeiro destes é que o ser humano, embora consciente de sua finitude - ao se dar conta da temporalidade presente enquanto processo em sua vida - , revela um desejo natural de permanecer na existência (Ep. LXXXII, 15-16; XX$\mathrm{XIV}, 8)$. Ademais, cumpre ressaltar que a imagem da morte vem sendo revestida, no decorrer dos séculos, por um aparato assustador, seja pela poesia, seja pela religião ou mesmo pelo imaginário coletivo. Tais descrições tornaram-na, aos olhos da maior parte dos seres humanos, um dos males mais nefandos ( $E p$. XXIV, 14). Talvez esta seja a razão pela qual Sêneca demonstre por esta temática um acentuado apreço em várias passagens de sua obra. Em De Brevitate Vitae, por exemplo, o autor sustenta que toda a vida é

\footnotetext{
${ }^{3} E p$. LXXXII, 16. Itaque etiam si indifferens mors est, non tamen ea est,quae facile neglegi possit. Magna exercitatione durandus estanimus, ut conspectum eius accessumque patiatur. Mors contemni debet magis quam solet.
} 
um aprender a morrer (Brev. VII, 3-4). E, posteriormente, nas Epistulae, o aprender a morrer se traduz num exercício cotidiano, a saber, a mediatio mortis $^{4}$.

\section{I.1 O que constitui a mors?}

A investigação amparada em pressupostos de caráter antropológico revela um fim coincidente ao ideal ético estoico: diagnosticar quais sejam, em verdade, as principais causas de temor para os seres humanos é tarefa que, por ter em vista o processo de re-valoração das referidas causas em indiferentes, pretende contribuir para que se alcance um estado de tranquilidade da alma. Ora, a convicção de que sofrimento e morte não constituem males tem o benefício de afastar o ser humano de estados psíquicos doentios e próximos da perturbação.

Neste sentido, Sêneca há de se dedicar ao exame atento e cuidadoso do que sejam, em verdade, os sentidos da morte e do sofrimento, procedendo, deste modo, a uma tarefa de classificação e categorização daqueles fenômenos. A estratégia de Sêneca, ao investigar a morte - considerado um indiferente dos mais ameaçadores da condição psíquica humana, haja vista se assemelhar verdadeiramente a um mal - será a de mirá-la atentamente, a fim de restituir-lhe suas verdadeiras atribuições, o que se dará mediante o exercício de meditação constante e diário que se definirá pela expressão latina cotidie mori.

O que vês ocorrer às crianças, também a nós, crianças grandes, ocorre: assustam-se com aqueles a quem amam, a quem se acostumaram, com quem brincam, se estes lhes aparecem mascarados. Não apenas aos seres humanos, mas às coisas, a máscara deve ser tirada e sua verdadeira face devolvida ${ }^{5}$

Uma vez posta diante de si, e arrancada sua máscara, a morte revelase como não sendo nem um bem nem um mal, mas apenas um indiferente não preferível. Mas em que sentido seria possível argumentar que a morte

\footnotetext{
${ }^{4}$ Vale registar aqui a possível influência de Platão no que se refere ao tema da morte em Sêneca, já que, no Fédon, filosofar também é aprender a morrer. Conferir, sobretudo, o passo 67 e da referida obra platônica.

${ }^{5}$ Ep. XXIV, 13. Quod vides accidere pueris, hoc nobis quoque maiusculis pueris evenit: illi quos amant, quibus adsueverunt, cum quibus ludunt, si personatos vident, expavescunt. Non hominibus tantum, sed rebus persona demenda est et reddenda facies sua.
} 
não constitui verdadeiramente um mal? Como atestar que a proposta de revaloração estoica não representa um mero ardil linguístico? Sêneca nos apresenta, ao mesmo tempo que nos propõe, suas armas para que possamos considerar a partir de outra perspectiva a definição e o fenômeno da morte.

Argumentos os mais variados são postulados por nosso autor para fazer frente a esta problemática. Num certo sentido, a fim de explicar em que medida a morte não constitui um mal, Sêneca parece adotar uma perspectiva quase que biológica ao examinar o referido fenômeno, ao afirmar que o mesmo coincide com o não-ser. Neste sentido, a morte é apresentada como algo para além de nossa existência, distante e desconhecido, e que se reverteria num fenômeno com o qual seria inútil nos preocuparmos (Ep. LIV, 4-5). A influência de Epicuro, aqui, é notória ${ }^{6}$.

Concebida a morte a partir da perspectiva de sua intrínseca relação com nossa existência, os argumentos acerca da necessidade de sua ressignificação são de dois tipos: num destes, o fenômeno representa o termo de nossa própria vida, pensada enquanto processo. Assim, não querer morrer seria não querer viver - afinal, como revoltar-se contra uma parte do processo, que deve ser tomado em sua integralidade? Pensando dessa maneira, a morte encontrar-se-ia misturada à própria vida e morreríamos um pouco a cada dia (Ep. LIV, 4-5). Num outro domínio, poderíamos agrupar as razões que Sêneca procura oferecer para argumentar que a dor ligada ao processo de morte não precisa ser temida, haja vista que ou se revelará muito intensa e breve, ou duradoura e suave ( $E p$. IV, 3).

Por fim, há ainda aqueles argumentos que apelam para o caráter abrangente da morte, lembrando que a mesma atingirá a todos e que, por este motivo, não faria sentido revoltarmo-nos com a divindade por conta do curto tempo que nos foi destinado, nem pelo fato de a mesma fazer parte da vida $(E p . \mathrm{XXX}, 11)$.

\footnotetext{
${ }^{6}$ Lembramos, a este respeito, a seguinte máxima de Epicuro: “A morte nada é para nós. Com efeito, aquilo que está decomposto é insensível, e a insensibilidade é o nada para nós", a qual se encontra na Carta a Meneceu. O filósofo parece querer enfatizar que, para que possamos lidar bem com a morte, seria necessário compreendermos a natureza das coisas e a morte representaria simplesmente um fenômeno de separação dos átomos componentes do organismo. In: Epicuro: máximas principais. Trad. João Quartim de Moraes. São Paulo: Loyola, 2013, p. 14.
} 
Vale lembrar que embora Sêneca busque elencar todos estes argumentos em favor da tese de que não faria sentido vivermos atemorizados e doentes por conta de nossa mortalidade, haja vista que ela não pode constituir um mal, o autor não parece exortar a que se adote uma conduta mórbi$\mathrm{da}^{7}$. Ora, o que ele faz a todo tempo é recomendar disposições de caráter fortes e corajosas diante das adversidades, sejam essas quais forem. Embora legitime a morte voluntária em circunstâncias nas quais a virtude se encontra ameaçada, esclarece que a vida é um indiferente preferível e elegível diante da morte e que, de um ponto de vista moral mais rigoroso, ambas não possuiriam valor - pois o que sempre há de se revestir de um valor positivo não são os atos em si, mas o modo como os enfrentamos. Na verdade, são as virtudes os únicos bens.

\section{A questão dos valores: o bem, o mal e os indiferentes;}

Importa-nos, antes de tudo, buscar compreender em que se fundamenta a tese senequiana de que fenômenos como a morte não representam, em verdade, nenhum motivo de perturbação para a alma humana. Uma tal asserção não parece, nem de longe, óbvia - necessitando, portanto, de um bom argumento para ampará-la.

Ocorre que a estratégia estoica, ao delinear os traços mais fundamentais da condição humana, busca explicar-se criando uma nova escala de valores na ética. Sendo assim, pensar o ser humano é também refletir sobre seus valores e, consequentemente, sobre suas escolhas. E é postulando uma nova categoria na escala de valores, a saber, a dos indiferentes, que os estoicos pretendiam não apenas sustentar posições como a de que a morte não constitui nem um bem nem um mal para o ser humano, mas, ainda, conciliar a teoria física do destino com a preservação do mérito na ação moral. Questões estas que não discutiremos aqui. Por ora, parece-nos suficiente que nos remetamos às definições mais gerais da axiologia estoica, a saber, aquelas que delimitam as noções como bem, mal e indiferentes. E, com relação es-

\footnotetext{
${ }^{7}$ Conferir, a respeito desta problemática, as seguintes passagens: Ep. XXIV, 23-24; XXX, 15. Do ponto de vista do tema da morte voluntária, contudo, Sêneca é uma exceção em relação aos demais estoicos.
} 
pecificamente à definição do bem estoico, lembramos as palavras de Sêneca:

“O que é?”, perguntas. É aquilo que é conforme a própria natureza. $\mathrm{O}$ bem de nenhum modo pode recair num animal sem discurso, pois é da natureza dos melhores e mais produtivos. A não ser onde a razão esteja localizada, o bem não está. Quatro tipos de seres há na natureza: a árvore, o animal, o humano e o deus; estes dois, porque racionais, têm a mesma natureza, apenas são diversos porque uma é imortal, a outra mortal. Disso, nesse sentido, para o deus, a natureza é seu bem específico; para o ser humano, o esforço. Os demais seres em sua natureza são perfeitos, mas não verdadeiramente perfeitos, pois neles a razão é ausente. De fato apenas é perfeito o que o é segundo a perfeição da natureza universal. E a natureza universal é racional ${ }^{8}$.

Como se vê, Sêneca retoma aqui um dos sentidos mais célebres do bem estoico: aquele que o define enquanto a conformidade com a própria natureza - o que, no caso do ser humano, corresponde a uma vida conforme a razão. A passagem é rica e merece mais destaque, sobretudo no que se refere a questões como a delimitação do conceito de razão aí envolvido e ao processo entendido como movimento necessário para o alcance da virtude, implícita no conceito de bem.

Importa salientar aqui que, uma vez entendido o bem como coincidente com a virtude e, neste sentido, com a disposição de viver em conformidade com a natureza, nota-se que o mesmo fica circunscrito à esfera moral. E assim como o bem será rigorosamente definido pela via da moralidade, o mal - ou vício -, em sua contraposição, também o será. O que implica dizer que o vício será caracterizado pelo conflito com a própria natureza, o que no caso do ser humano diz respeito à sua natureza racional.

Para além da discussão se a ética estoica é ou não sobre-humana inclusive na medida em que aproxima demasiadamente seres humanos e deuses, criando expectativas extremamente elevadas para aqueles - importa aqui, a fim de detalhar ainda mais o problema, apresentar a categoria dos in-

\footnotetext{
${ }^{8}$ Ep. CXXIV, 13-14 “Quod est?” Inquis. Hoc, quod secundum cuiusque naturam est. Bonum quidem cadere in mutum animal nullo modo potest; felicioris meliorisque naturae est. Nisi ubi rationi locus est, bonum non est. Quattuor hae naturae sunt, arboris, animalis, hominis, dei; haec duo, quae rationalia sunt, eandem naturam habent, illo diversa sunt, quod alterum inmortale, alterum mortale est. Ex his ergo unius bonum natura perficit, dei scilicet, alterius cura, hominis. Cetera tantum in sua natura perfecta sunt, non vere perfecta, a quibus abest ratio. Hoc enim demum perfectum est, quod secundum universam naturam perfectum, universa autem natura rationalis est.
} 
diferentes, aquela que é originalmente estoica e que abarca tudo o que não se caracteriza por constituir um bem ou um mal. Uma definição baseada nas palavras do próprio Sêneca pode ser encontrada na epístola LXXXII:

De um quarto dizemos que é claro, embora o mesmo se torne escuríssimo com a noite. O dia a ele infunde luz, a noite lha tira. Dessa forma, com estas coisas, que nós dizemos indiferentes ou intermediários, com riqueza, força, aparência, honras, poder e, ao contrário, com morte, exilio, males e dores e outros que menos ou mais tememos. Ou a má vontade ou a virtude que lhes confere o nome de bem ou de mal $^{9}$

Como se vê, para tornar mais claro ao interlocutor o caráter acidental dos indiferentes frente à moralidade, nosso autor lança mão de uma comparação. O quarto em si, não tem luz ou escuridão inerentes a si próprio: é o dia ou a noite quem lhe hão de conferir ou destituir a luz. Em ordem contrária e inversa, será a nossa disposição de espírito virtuosa quem marcará um dado ato ou fenômeno com o traço do bem. $\mathrm{O}$ ato ou o fenômeno, em si, são indiferentes. A nossa disposição de espírito - interior a nós mesmos, exterior com relação a estes atos ou fenômenos - é o que realmente conta, no que se refere à moralidade $\mathrm{e}$, consequentemente, ao bem.

Sendo assim, de um ponto de vista mais amplo, os indifferens ou media são aqueles que se caracterizam por não serem bens, nem males ou por estarem em uma posição intermediária com relação a estes. A definição é genérica, mas expressa muito bem o que o autor parece ter em mente: para além daquilo que realmente conta para a moralidade, i.é, bem e mal, os indiferentes hão de abarcar tudo. O que representa dizer que os ditos bens externos, aqueles que são tão bem avaliados pela maior parte das pessoas, são apenas pretensamente bens. $\mathrm{O}$ que também equivale a dizer que tudo aquilo que normalmente causa repulsa e aversão à maior parte das pessoas também não constitui, em verdade, um mal. Ora, estariam os estoicos propondo apenas um novo jogo de palavras para compreender coisas já problematizadas anteriormente $^{10}$, ou seja, para dar conta de um problema já levantado e res-

\footnotetext{
${ }^{9}$ Ep. LXXXII, 13-14. Cubiculum lucidum dicimus, hoc idem obscurissimum est nocte. Dies illi lucem infundit, nox eripit; sic istis, quae a nobis ac media dicuntur, divitiis, viribus, formae, honoribus, regno et contra morti, exilio, malae valetudini, doloribus quaeque alia aut minus aut magis pertimuimus, aut mal itia aut virtus dat boni vel mali nomen.

${ }^{10}$ Se por um lado talvez pudéssemos considerar que, para Platão e Aristóteles, as riquezas e as honrarias também não constituiriam o bem; por outro, é importante lembrar que os referidos filósofos não chegaram a criar uma categoria ética que abarcasse tais elementos - tal
} 
pondido? Se não é o caso, e a proposta destes autores é legítima, por que razão a maior parte das pessoas sente, de fato, desejo por bens externos e repulsa pelos ditos males e sofrimentos?

A este respeito, algumas considerações podem ser tecidas. A resposta mais imediata dos estoicos é introduzir na categoria dos indiferentes uma nova divisão, a saber, aquela que diferencia dentre aqueles os preferíveis e os não preferíveis (LS58DE). Alguns dentre os indiferentes, tais como “morte, exílio, problemas de saúde, dor", são, para os seres humanos, não preferíveis. Por outro lado, obviamente, "riqueza, força, beleza, carreira das honras, poder" são preferíveis. O critério que os distingue será - como sempre - a pedra de toque da ética estoica: será preferível tudo aquilo que é conforme com a nossa natureza e, não preferível, o que não o é. A título de exemplo, pensemos no caso da morte: trata-se aqui de um não preferível. Ora, é o próprio Sêneca quem afirma que o ser humano revela um desejo natural de permanecer na existência.

Há, Lucílio, naquilo a que chamamos de intermediário, grande diferença. De fato, não é a morte indiferente do mesmo modo do que se ter um número par ou ímpar de cabelos. A morte está entre aquelas coisas que não são males, ainda que tenham esta aparência; pois o amor próprio e a vontade de conservação permanente, também a repugnância pela dissolução, porque (a morte) parece muitos bens nos tomar, além de nos tomar coisas a que estamos acostumados ${ }^{11}$

Assim, fica claro que o termo 'indiferente' carrega consigo dois sentidos, conforme o autor explica: um deles, relativo ao sentido habitual com que lidamos com algo para o qual não damos a mínima importância, algo que nos é, por assim dizer, indiferente. Numa outra perspectiva, tratamos com coisas ou eventos cuja sorte nos importa e muito - como é o caso de nossa vida ou nossa morte, mas que, por si mesmos, não são capazes, absolutamente, de exercer qualquer tipo de interferência naquilo que realmente nos define como seres humanos, i.é, o vínculo que possuímos com nossa natureza racional, o qual estipula nossas disposições morais. Com relação aos

como o fizeram os estoicos, que conferiram aos indiferentes importância substancial em sua teoria ética.

${ }^{11}$ Ep. LXXXII, 15. Est et horum, Lucili, quae appellamus media, grande discrimen. Non enim sic mors indifferens est, quomodo utrum capillos pares an inpares habeas. Mors inter illa est, quae mala quidem non sunt, tamen habent mali speciem; sui amor est et permanendi conservandique se ínsita voluntas atque aspernatio dissolutionis, quia videtur multa nobis bona eripere et nos ex hac, cui adsuevimus, rerum copia educere. 
indiferentes, poderíamos resumir: alguns o são do ponto de vista de nos sentirmos atraídos ou repelidos por eles; outros, no sentido de que a vida feliz independe de sua posse ${ }^{12}$.

Outras questões poderiam ainda ser discutidas acerca da problemática que envolve os media na doutrina estoica. Embora não pretendamos nos alongar aqui, vale lembrar a interessante proposta de interpretação esboçada por Tad Brennan ${ }^{13}$, para quem os indiferentes não constituiriam um mero amontoado a agrupar tudo o que não depende de nós, antes pelo contrário, já que seria justamente no ato de ser defrontado com esta categoria de valores que o ser humano teria de exercitar sua capacidade de observação e de seleção. Assim, muitas vezes, este exercício representaria a oportunidade de se intensificar o processo de transformação do proficiens. Enfrentar a todas as situações ditas indiferentes, regulando a própria disposição de espírito, sempre com vistas à virtude e à conformação com a natureza humana racional, constituiria, assim, o objetivo maior e importante passo na direção de nossa transformação moral.

\section{A posição da escola: a noção de impressão estoica}

O problema da impressão (phantasia) no estoicismo constitui temática que extrapola os domínios permeados por questões de ordem epistêmica, abarcando, ainda, perspectivas éticas e relativas à teoria da ação. Ora, o fenômeno do assentimento, sob a perspectiva do processo que mobiliza o ser humano para a ação, ocorrerá em seguida a fenômenos como o pensamento acerca de dada impressão provocada por algum objeto, e da própria impressão.

Neste sentido, Crisipo parece ter definido a impressão (phantasia) como uma espécie de afecção que se produz na alma e que se revela a si mesma e também a aquilo que a produziu (SVF II, 54; LS 39B). A este res-

\footnotetext{
${ }^{12}$ A tese que postula dentre os indiferentes a divisão entre preferíveis e não preferíveis encontrou objeções já em meio à própria escola estoica, tornando-se uma querela entre seus representantes. Conferir, a este respeito, os seguintes fragmentos SVF I, 131; SVF III, 137.

${ }^{13}$ Ver a este respeito, os seguintes artigo e capítulo de livro, respectivamente: BRENNAN, T. Psicologia estóica. In: INWOOD, B. (Org.). Os estóicos. Trad. Raul Fiker. São Paulo: Odysseus Editora, 2006, p. 285-326; BRENNAN. T. Psicologia. In : A vida estoica : emoções, obrigações e destino. Trad. Marcelo Consentino. São Paulo : Loyola, 2010, p. 61117.
} 
peito, duas metáforas foram formuladas pelos estoicos para ilustrar o conceito em questão: a da luz (phôs), que também se revela, além de revelar aquilo sobre o qual se lança e clarifica; e a da impressão, pensada aqui como a marca deixada por um objeto sobre a superfície daquilo a que se sobrepõe (pensemos aqui no exemplo do selo). Segundo Crisipo, o maior inconveniente desta última metáfora seria a margem que daria a uma concepção de alma como matéria inerte - e o autor, neste sentido, tendia a pensar que, ao contrário, este processo era marcado por modificações da alma (SVF II 52, 55, 61; LS39A).

Uma impressão não seria uma crença - seria antes a impressão da realidade de alguma coisa. Ora, uma crença sobre algo se constituiria a partir do assentimento dado à uma impressão (LS 41A). Outro aspecto importante que merece ainda ser destacado no tocante a esta temática é que a phantasia tem de ser distinguida do phantasma: a impressão é sempre causada por um objeto, o que não é o caso quando o que está em jogo é a imaginação.

Além disso, impressões podem acometer seres viventes racionais e não-racionais. No caso dos primeiros, elas darão origem aos processos de pensamento, através dos quais, pela comparação, se formarão as noções das coisas. Neste sentido, Long e Sedley sugerem que "todas as impressões de seres humanos adultos são concebidas como tendo um conteúdo proposicional", de modo que "damos nosso assentimento às impressões, o dando aos lektá ou proposições que lhes correspondem" (LONG, A.; SEDLEY, D., 2001, p. 184). Desse modo, impressão e linguagem seriam formas de interpretação da experiência humana.

O termo latino visum, correspondente do grego phantasia, pode designar tanto a visão, i.é, o ato de perceber pelos olhos, quanto o objeto visível, ou seja, a imagem. Neste sentido, Sêneca se valerá do referido vocabulário nas circunstâncias as mais diversas. Selecionamos, entretanto, um passo das Epistulae, o qual consideramos rico em elementos para a discussão do referido problema, segundo a perspectiva senequiana. Ei-lo: 
Queres saber se todo bem é desejável. Dizes: "Se é um bem suportar ser torturado, ser queimado com grande valentia e pacientemente adoecer; se tais coisas são desejáveis. Porém, nada vejo delas que seja digno de desejo" (...). Analisa, meu Lucílio, essas coisas, e compreenderás que nelas há algo de desejável ${ }^{14}$

O contexto em questão é o da epístola LXVII, na qual Sêneca procura convencer Lucílio de que todo o bem é desejável, inclusive a coragem, aí entendida enquanto capacidade de tolerar todas as adversidades. Note-se a este respeito que, quando o autor simula uma fala de seu discípulo, se vale do verbo video, ou seja, tem em mente o modo como eventos tidos pela maior parte dos seres humanos como males - a tortura, as chamas e a doença se mostram para Lucílio. Trata-se, aqui, do modo como ele os vê. Logo ao término da fala do discípulo, Sêneca esboça sua reação argumentativa: seu conselho é o de que Lucílio aplique a tais eventos seu discernimento (distinguo) e sua compreensão (intellego). O que Sêneca tem em mente, fica bastante claro, quando exposto logo a seguir, ao fim do quarto passo daquela epístola: "Não são as circunstâncias adversas que são desejáveis, mas sim a virtude que nos permite ultrapassar essas circunstâncias adversas" (Ep. LXVII, 4). Para que se possa compreender do que se trata, é preciso discernir o ato do modo como o enfrentamos: neste sentido, ter de ser torturado ou ter de estar doente, não são atos desejáveis. Mas enfrentá-los virtuosamente, i.é, aceitando-os com magnanimidade e tranquilidade, certamente, é desejável, como o são todos os bens.

Noutro contexto, o da epístola LXXIV, encontramos outro passo sugestivo, quando Sêneca desenvolve argumentação relativa à tese semelhante àquela da epístola LXVII. O autor, aqui, procura explicar porque aquilo a que chamamos bens exteriores não devem em verdade ser considerados bens - pela via negativa, o autor argumenta que, se o fossem, seres humanos seriam mais felizes que deuses e animais mais felizes que seres humanos. Ora, isto seria absurdo.

\footnotetext{
${ }^{14}$ Ep. LXVII, 3-4. Quaeris, an omne bonum optabile sit. "Si bonum est", inquis, "fortiter torqueri et magno animo uri et patienter aegrotare, sequitur, ut ista optabilia sint. Nihil autem vídeo ex istis voto dignum. Neminem certe adhuc scio eo nomine votum solvisse, quod flagellis caesus esset aut podagra distortus aut ecúleo longior factus". Distingue, mi Lucili, ista, et intelleges esse in iis aliquid optandum.
} 
Inclui que muitas coisas que são vistas como boas atingem muito mais plenamente animais do que seres humanos. Aqueles com muito mais avidez utilizam o alimento, fatigam-se pelo excesso de sexo, e o vigor de suas forças é mais constante. Consequentemente, mais felizes são que muitos seres humanos ${ }^{15}$.

Novamente, o termo video é aqui atribuído ao modo como tomamos coisas e eventos do mundo que nos circunda. Sêneca argumenta, então, para mostrar porque é absurdo entender aquelas coisas que são pretensamente tomadas como bens, como bens de fato. Ora, o verdadeiro bem, aqui considerado, deve ser relacionado ao que melhor caracteriza o ser humano, a saber, o seu traço racional. E, numa dada perspectiva, a relação de felicidade deveria ser invertida: gozariam de maior tranquilidade e felicidade, aqueles que mais participassem da razão.

Todo o tema da impressão nos leva, sobretudo a partir da leitura e problematização deste último trecho, a uma nova questão a qual importa aqui ser colocada: a ética estoica, pensada principalmente como uma proposta de releitura dos valores - uma nova leitura fundamentada na escala de valores formulada pela própria escola - não constituiria uma solução extremamente intelectualista? Isto é, a correção de erros de ordem moral não se reduziria, neste apelo desmedido à razão, a uma reforma de paradigma de fundo sobretudo epistêmico? Se for o caso, o problema não redundaria, sobretudo em Sêneca, numa incoerência absurda, dada sua afeição e seu apelo a recursos retóricos na lide com questões morais? Afinal de contas, o problema da correção das impressões é de ordem meramente moral, meramente epistêmica, ou pertence a ambos os domínios? De resto, a questão é das mais complexas, e não poderíamos levar em conta uma só perspectiva ao abordá-la.

Que o dito intelectualismo presente em algumas teses estoicas parece claramente expresso, não há dúvidas: o monismo psicológico e a principal premissa decorrente desta concepção psíquica humana - viver em conformidade com a natureza racional - a um só tempo nos atestam o apelo estoico à razão. Resta, para ilustrar melhor o problema, discutir que tipo de razão está aí em jogo.

\footnotetext{
${ }^{15}$ Ep. LXXIV, 15. Adice, quod multa, quae bona videri volunt, animalibus quam homini pleniora contingunt. Illa cibo avidius utuntur, venere non aeque fatigantur, virium illis maior est et aequabilior firmitas. Sequitur, ut multo feliciora sint homine.
} 
Para além destas questões, a já discutida problemática referente ao exagerado uso de recursos retóricos da parte de Sêneca poderia vir a refletir aqui um problema ou uma incoerência. Em todo caso, as próprias palavras de Sêneca nos atestam que a sabedoria é conquistada através de treino e muito esforço ${ }^{16}$.

O caso da morte, a este respeito, é emblemático: trata-se de fenômeno cuja compreensão recomendada pelo estoicismo não depende de mera tradução ou interpretação racionais - entendidas estas como uma correção de um raciocínio deformado. Ora, o próprio Sêneca, em sua obra, nos ilustra de forma vívida que se trata de um fenômeno com o qual devemos lidar com o maior cuidado e à custa de intenso treino diário. Trata-se aqui, de querermos ver a morte com outros olhos, de passarmos, gradativamente, de um estado psíquico no qual o simples ato de pensar nela nos perturba, a uma disposição de franca serenidade frente a tudo o que pode nos advir. Neste sentido, toda e qualquer iniciativa moral perpassa o âmbito da vontade.

Caso se trate, portanto, de conciliar duas perspectivas distintas, ambas irremediavelmente vinculadas ao conceito de razão, entendido aqui como natureza da alma humana, importa compreender em que medida os estoicos - e aqui, sobretudo Sêneca - foram capazes de flexibilizar tal noção, a fim de que ela desse conta de suportar a tensão inerente ao problema em questão. Mais reflexões nesta direção serão apresentadas a seguir, quando trataremos do método empregue por Sêneca no procedimento de cura das afecções da alma.

\section{A proposta de terapia senequiana}

Mas embora estirado na mesma enfermaria, falo contigo dos males que temos em comum, e os remédios comunico. Assim, ouve-me, como se eu estivesse a falar comigo mesmo: em meus retiros e, tendo sido tu admitido, comigo mesmo discuto ${ }^{17}$

\footnotetext{
${ }^{16}$ É importante ressaltar que o estado de tranquilidade da alma é alcançado por um processo, no qual a instância da vontade assumirá papel de considerável importância. Não se adquire a capacidade de julgar de acordo com a razão sem um indizível esforço. Lembramos, a este respeito, as palavras do próprio Sêneca: "Desse modo, insistamos e perseveremos: resta mais do que já abatemos, mas a maior parte do progresso é querer progredir. De uma coisa sou para mim consciente: quero e quero com toda a alma" (Instemus itaque et perseveremus; plus quam profligavimus restat, sed magna pars est profectus velle proficere. Huius rei conscius mihi sum: volo et mente tota volo). Cf. Ep. LXXI, 36.

${ }^{17}$ Ep. XXVII, 1. Non sum tam inprobus, ut curationes aeger obeam, sed tamquam in eodem valitudinario iaceam, de communitecum malo conloquor et remedia communico. Sic itaque me audi, tamquam mecum loquar. In secretum te meum admito et te adhibito mecum exigo.
} 
Pequeninos e amedrontados que nos mostramos diante da fúria da Natureza, travestida sob os desmandos da fortuna, poderíamos nos perguntar, muitas vezes, se não estaríamos à mercê de uma força absurda e irracional, que nos trai ao atuar cegamente e a traçar, para nossas vidas, um destino inexorável - ao invés de constituirmos parte de uma razão ordenadora e inteligente, como gostaríamos que fosse o caso. ${ }^{18}$

Grandiosos e fortes, capazes de amar a Razão e de querê-la, a ponto de querer o mesmo a que ela tanto aspira. A ponto de conformar nossa vontade, a tudo o que ela queira. Nesta perspectiva, seríamos parcela pequenina de amor, já que a Razão a tudo é imanente, e a tudo deseja, intensamente.

Pois, trata-se, aqui, obviamente, de duas perspectivas distintas, i.é, de duas interpretações dadas a um mesmo problema: o da nossa colocação no mundo, ou mesmo o de nossa missão como seres humanos. A primeira perspectiva parece refletir a interpretação da maior parte dos seres humanos acerca de sua condição trágica no mundo. A segunda, por sua vez, poderia refletir a interpretação que dá dos fatos e eventos aquele que já desenvolveu plenamente a sua natureza humana: está em conformidade com o elemento dominador de sua alma, que é a razão. A este, de tão rara estirpe, chamaríamos sábio, ou ao menos alguém que muito já caminhou nesta direção.

Sêneca, como bom estoico, não nega que as adversidades com as quais iremos nos deparar em vida, em muitos casos, assemelham-se a males terríveis. É importante lembrar que nosso autor era um escritor de apelo popular e que, também por isso, sempre tendia a escrever em linguagem menos rigorosa que a dos demais estoicos. O próprio filósofo, como se sabe, estava longe de se considerar um sábio, tomando-se sempre como um proficiens ou progrediens. Assim, a Sêneca parece legítimo considerar que eventos como a morte - revestidos da aparência de mal - tivessem, em verdade, de ser considerados com maior cuidado. A este respeito já discorremos em tópico anterior. A questão que merece aqui ser lembrada é que a maior parte de nós tende a deixar-se perturbar por tais perspectivas, o que poderia constituir, em muitos casos, um complicador do ponto de vista moral, tendo em vista o ideal ético estoico da tranquillitas animi.

\footnotetext{
${ }^{18}$ Sêneca, na epístola LXXIV, nos convida a guardar no espírito a imagem da fortuna, sempre a brincar com os seres humanos, espalhando entre estes, ao acaso, honras e riquezas. Ep. LXXIV, 7.
} 
Mas, o que importa então considerar é que, uma vez que estamos todos sujeitos a adversidades e que a maior parte de nós tende a perturbar-se a partir desta condição trágica, revelando, assim, uma perigosa limitação no modo de interpretar o mundo circundante, faz-se necessária, segundo a perspectiva estoica, uma revisão de valores, i.é, uma cura no modo de interpretar coisas e eventos do mundo circundante.

Que uma importante estratégia da escola estoica será a de introduzir na escala de valores a então inédita categoria dos indiferentes, e assentar nesta base a argumentação da tese de que a morte é um indiferente, é problemática que já explicitamos. Importa agora verificar como Sêneca há de lidar com esta questão. Isto é, verificar em que medida o filósofo romano há de formular, a seu modo, um método de cura para aquelas almas que tendem a interpretar de modo equívoco o mundo.

A therapeia ou cura a que Sêneca costuma fazer alusão em algumas de suas Epistulae ${ }^{19}$, consiste, de modo bastante simples, num cuidado ou cultivo da própria alma e só pode ser empreendido por meio da filosofia - devendo refletir-se, tão logo, no agir ético humano. A epístola LXXXII parece ser esclarecedora a este respeito, uma vez que define dois aspectos deste método filosófico a ser empreendido na cura das afecções da alma. Segue trecho que define com precisão um destes aspectos:

A filosofia deverá circundar-nos, como muralha inexpugnável, à qual a fortuna, embora provoque com muitas máquinas de guerra, não atravessa. (...) Não tem a fortuna, como pensamos, longas mãos e a ninguém alcança se perto dela não estiver. E assim, o quanto pudermos, para longe dela saltemos, o que só se cumprirá pelo conhecimento de si e da natureza ${ }^{20}$.

Trata-se, no trecho acima descrito, da importância do conhecimento do verdadeiro sentido das coisas/ eventos mundanos, na tarefa moral. Neste sentido, a proposta de Sêneca é aquela que procuramos explicitar em tópico anterior: a de arrancar das coisas suas máscaras e procurar traçar seus limi-

\footnotetext{
${ }^{19}$ Conferir, a este respeito, os seguintes passos: Ep. XXVII, 1; LII, 10; LXVIII, 7; XCIV, 36.

${ }^{20}$ Ep. LXXXII, 5-6. Philosophia circumdanda est, inexpugnabilis murus, quem fortuna multis machinis lacessitum non transit. In superabili loco stat animus, qui externa deseruit, et arce se sua vindicat; infra illum omne telum cadit, Non habet, ut putamos, fortuna longas manus; neminem occupat nisi haerentem sibi. Itaque quantum possumus, ab illa resiliamus; quod sola praestabit sui naturaeque cognitio.
} 
tes, i.é, defini-las segundo os critérios da razão. No caso da morte, Sêneca havia procurado explicitar, através de diferentes perspectivas, sentidos da morte que não lha revestissem de aspectos sombrios ou aterradores. A morte consistiria num mero indiferente, tendo em vista que o único critério importante no agir humano, aquele que atuaria como divisor e atribuidor de valores, seria o da moralidade, i.é, o da conformidade com a virtude (Ep. LXXXII, 15-17).

Pois bem, ocorre que, se seguirmos adiante na leitura da supracitada epístola, encontraremos desta vez outro trecho bastante esclarecedor a respeito da problemática em questão, se tomarmos em consideração o seu oitavo passo. Após afirmar que o ser humano deve demonstrar aquilo que sabe sobretudo quando a vida lhe chama a fazê-lo, i.é, diante das adversidades, Sêneca nos alerta que "a assídua meditação fará firme o ânimo, se exercitares não as palavras, mas sim a alma - então, te prepararias para a morte" ${ }^{21}$.

Ora, o filósofo, aqui, desloca o eixo no qual a terapêutica estoica estava centrado, revelando que a busca pelo aprimoramento moral não constitui apenas conhecimento, mas, ainda, ação. O conhecimento que não é interiorizado e praticado, portanto, não teria valor. A este respeito, a epístola LXXXII é esclarecedora: a meditatio mortis, método no qual o proficiens busca preparar-se para a morte, envolve treino e muita meditação. Não basta compreender que a morte é um indiferente, é necessário convencer-se disso. Ora, situações reais de nossa vida, tais como a experiência da morte, envolveriam uma complexidade muito maior que aquela formulada num silogismo, entendido como mera combinação de palavras - e exigiriam, para tanto, uma disposição de espírito apenas alcançada com elevada dedicação e intenso esforço ${ }^{22}$.

Daí a importância dos exemplos e das analogias aos quais Sêneca tanto recorrerá em sua obra. Não serão poucas as ocasiões em que o autor,

\footnotetext{
${ }^{21} \mathrm{Ep}$. LXXXII, 8. Faciet autem illud firmum adsidua meditatio, si non verba exercueris, sed animum, si contra mortem te praeparaveris.

${ }^{22}$ A epístola LIV ilustra, com bastante propriedade, nos passos 3, 4, 5 e 6, o método em questão: Sêneca ali nos revela a que estratégias recorreu, durante uma crise de asma, para se acalmar diante do temor da morte. O filósofo recorda argumentos tais como aquele que compreende a morte como não-ser, e se vale de uma analogia para tornar mais compreensí vel a noção de morte e vida como constituindo um e mesmo processo. Sêneca esclarece que seria apenas recorrendo a pensamentos desta ordem que se poderia insuflar em si mesmo coragem, através de um processo lento e gradual. Conferir Ep. LIV, 3-6; e, também, a este respeito, Ep. IV, 2-9; XXIV, 1-3.
} 
após buscar uma tratativa de problemas de ordem tradicional, i.é, recorrendo a argumentos já anteriormente formulados e desenvolvidos pela escola e assentados sobretudo em bases lógicas, lançará mão de estratégias de apelo retórico, no intuito, sobretudo, de convencer o interlocutor, de proceder a uma mobilização efetiva.

Entretanto, a questão que aqui se coloca revela-se mais complexa e ampla quando se percebe que o método proposto por Sêneca não parece se restringir a uma opção por um modo de cura das afecções de alma. Antes disso, o método aqui considerado parece convergir para o próprio sentido que Sêneca atribui ao da atividade filosófica. Fazer filosofia e proceder na cura de afecções da alma, tendo em vista o alcance de um estado de tranquilidade da alma aqui representam uma mesma tarefa.

Pois bem, a partir de tais considerações, surge o seguinte problema: estaria Sêneca, em verdade, estabelecendo uma relação conflituosa com a argumentação lógica formal? Tendo em vista o modus operandi filosófico de Sêneca, seria razoável considerar que o filósofo compreenderia a lógica e muitos de seus recursos como instrumentos insuficientes diante dos desafios apresentados pela complexidade da vida humana - de modo que, para lhes fazer frente, necessitaríamos antes de ter o espírito forte e convicto, imbuído de seus valores, que ciente deles? Ora, se de fato é o caso, surge a seguinte questão: qual seria a verdadeira posição de Sêneca frente ao modo de se fazer filosofia? O autor despreza em absoluto a contribuição lógica na busca pelo sentido verdadeiro das coisas, demonstrando enorme apego e inclinação aos apelos retóricos ou prefere ainda buscar uma conciliação entre tais aspectos?

Poderíamos adotar a interpretação de que Sêneca entende que elementos lógicos são necessários, mas não suficientes para o convencimento, que seria o elemento mais importante para a mudança de disposição e, consequentemente, para a ação moral. Ora, mas como conciliar estas considerações, i.é, de que do ponto de vista moral, elementos retóricos poderiam ser tão ou mais importantes que os lógicos? Elas se revelariam contraditórias ao princípio estoico de que a alma é toda racional? Mostrar-se-iam pouco filosóficas, se concebermos a filosofia como uma atividade de encadeamento de raciocínios em busca do sentido das coisas? 
Tais questionamentos poderiam certamente ser levantados a respeito do método do qual Sêneca lança mão para elaborar seus escritos filosóficos. De fato, a tendência retórica demonstrada pelo autor lhe fez pagar um alto preço, tendo sido criticado e julgado como um autor de pouca capacidade especulativa durante largos períodos da História da Filosofia ${ }^{23}$. Tamanha é a importância deste debate para a discussão sobre a contribuição de Sêneca para a filosofia estoica, que gostaríamos de nos ater rapidamente a esta problemática.

\section{IV.1 Uma querela sobre o método filosófico de Sêneca}

Com relação à temática do método do qual lança mão Sêneca ao fazer filosofia, há uma importante querela entre dois intérpretes que merece ser aqui mencionada - sobretudo por tocar de perto em temas relevantes para o desenvolvimento deste estudo. A referida querela é travada por iniciativa de Betancur-Gomez, em resposta a um artigo anteriormente publicado por Cooper. Buscaremos apresentar, ainda que sucintamente, o que nos parece mais relevante na argumentação destes dois autores.

Cooper, em Seneca On Moral Theory and Moral Improvement ${ }^{24}$, formula uma crítica aos procedimentos de Sêneca enquanto filósofo estoico, alegando que o mesmo procura, em seu processo como guia espiritual de seu interlocutor, contribuir para a melhoria de sua compreensão de verdades filosóficas, embora valendo-se de apelos retóricos.

O autor entende que, do ponto de vista moral, para o estoicismo, de um modo geral, o bom estado de alma de alguém depende do entendimento de verdades fillosóficas. E, nesta direção, a única forma de melhorar as crenças de alguém seria lhe dar melhores razões ${ }^{25}$. Em decorrência desta tese ética fundamental, o autor sugere que Sêneca encontra-se numa posição incômoda, já que busca dar razões para que seus interlocutores compreen-

\footnotetext{
${ }^{23}$ São inúmeras as críticas dirigidas a Sêneca, seja como homem público, seja como pensador. A este respeito ver, por exemplo, BRUN, J. O estoicismo. Trad. João Amado. Lisboa: Edições 70, 1986, p. 23; e BRIDOUX, A. Le stoicisme et son influence. Paris : J. Vrin, 1966, p.166.

${ }^{24}$ Cf. COOPER, J. Seneca On Moral Theory and Moral Improvement. In: VOLK \& WILliAMS. Seeing Seneca Whole: Perspectives on Philosophy, Poetry and Politics. Leiden: Brill, 2006, p. 43-55.

25 Ibid., p. 45.
} 
dam a verdade, imbuído, sobretudo, por estratégias de apelo retórico. O problema é que uma teoria racionalista como a estoica, não suportaria uma tal perspectiva, e aí, a mera convicção não seria suficiente no processo de iniciativa moral ${ }^{26}$. O autor ainda comenta que, ao levantar tal polêmica, Sêneca não teria compreendido o valor real do estudo da lógica para a vida moral e estaria, assim, se afastando dos antigos estoicos e fazendo um estoicismo de outra ordem, ao tentar cortar as bases sobre as quais toda e qualquer reforma moral visando a vida feliz seria possível.

Betancur-Gomez, por sua vez, escreve um artigo intitulado Filosofia y Ejercicio Del Alma en las Cartas a Lucilio de Séneca ${ }^{27}$, no qual, em diálogo direto com Cooper, observa que este havia acusado o referido filósofo de menosprezar o valor do conhecimento filosófico apoiado em razões. Para Betancur-Gomez, Cooper tende a julgar Sêneca a partir de critérios externos às Epistulae, sem se perguntar em que realmente consistia o uso da razão em sua filosofia. E é assim que ele procura definir o sentido da filosofia para o autor romano, argumentando que, pelo fato de a mesma ter de ser acessível a todos, teria também de cuidar para apresentar razões acessíveis a todos. O problema é que aceitar a validade de um argumento - por exemplo, sobre a morte como indiferente - não é suficiente para persuadir ${ }^{28}$. O conhecimento teria de se submeter ao exercício. Betancur-Gomez, então, expande o conceito de razão aí envolvido e propõe uma chave de leitura para a máxima estoica de viver em conformidade com a razão, i.é, com a natureza: para o intérprete, trata-se, aí, de uma demanda por coerência entre conhecimento e ato. Além disso, o intérprete ainda argumenta em favor de que o método de Sêneca não representa um desprezo às razões lógicas, mas uma crítica aqueles que usam o silogismo para forçar o assentimento, sem persuadir ${ }^{29}$, o que não constituiria, absolutamente, um desprezo pela dialética ${ }^{30}$ - argumentação

\footnotetext{
${ }^{26}$ Ibid., p. 47-48

${ }^{27}$ Cf. BETANCUR-GOMEZ, J. C. Filosofía y ejercicio del alma en las Cartas a Lucilio de Séneca. Revista Pensamiento y Cultura, Vol. 15-2, Diciembre de 2012, p. 123-133.

28 Ibid., p. 127.

${ }^{29}$ Ibid., p. 129

${ }^{30}$ Perspectiva que parece se coadunar, em alguma medida, com a de Barnes, na medida em que este intérprete problematiza a posição de Sêneca - quase sempre considerada largamente hostil - com relação à lógica, apontando passagens em que se poderia depreender que suas críticas se direcionavam antes a tudo aquilo que poderia constituir uma distração para as questões verdadeiramente relevantes, que são as morais, que contra o estudo de questões lógicas por si mesmo. Cf. BARNES, J. Logic and the imperial Stoa. Leiden; New York;
} 
à qual Betancur-Gomez procede ao exemplificar, passo a passo, o método de Sêneca. Concluindo e retomando Hadot, o intérprete assenta sua argumentação numa interpretação da filosofia como modo de vida, o que não parece, em todo caso, estar muito distante do que de fato pensava Sêneca.

$\mathrm{O}$ que nos parece digno de nota nas duas argumentações exporemos brevemente a seguir. Em primeiro lugar, com relação a Cooper, parece-nos que o autor compreende muito bem, i.é, intui de forma bastante perspicaz, um dos mais importantes problemas da ética estoica, que é aquele referente às implicações éticas e psicológicas ou ainda éticas e epistêmicas da iniciativa moral: o comportamento do ser humano apenas reflete e ou deriva de um estado de alma. O que também implica dizer que o estado de alma, dependeria, por sua vez, do entendimento de verdades filosóficas - no caso, das teses defendidas pela escola estoica. Ora, a questão levantada pelo autor sobre a inconsistência ou não do modo de fazer filosofia senequiano - tendo-se em conta a tese da alma inteiramente racional formulada pelos antigos estoicos - mostra-se, portanto, absolutamente legítima. Ocorre que a crítica de Betancur acerca do método de Cooper também se mostra legítima: ele parece incorrer no perigoso engano de querer explicar Sêneca a partir de fundamentos externos aos seus escritos. É claro que devemos tratar Sêneca como um estoico. Mas é preciso tentar, antes de tudo, procurar em seu próprio texto elementos que o defendam de fáceis e - talvez - aparentes contradições. O que nos parece é que Cooper parece tomar a todo tempo o conceito de razão aí envolvido de modo muito delimitado e restrito: ela constitui faculdade que apenas procede, na interpretação e no diálogo com o mundo circundante, operando através de raciocínios lógicos. Em todo caso, parece ser este o mesmo problema que ainda permanece em aberto na argumentação de Betancur-Gomez. A despeito de tantas observações relevantes e acertadas, com as quais concordamos - como as de que Sêneca não revela desprezo pela argumentação lógica tradicional, apenas entende que ela não seja suficiente para lograr persuasão ${ }^{31}$; e a de que o conhecimento deve se

Köln: Brill, 1997, p. 19.

31 De fato, Sêneca parecia estar direcionando sua crítica ao discurso vazio, e não à argumentação formal, entendida de um modo geral. É preciso considerar que, para um autor que tinha em sua mais alta conta a integração entre o discurso e a sua aplicação, visando a utilidade da filosofia na vida prática, a mera utilização da argumentação formal, com fins exclu- 
submeter ao exercício $(E p . \mathrm{XX}, 1)$ - o autor, ao que nos parece, ainda deixa em aberto uma questão. Ora, se a alma se constitui puramente de razão, conforme propuseram os antigos estoicos (e sobre o que ainda não estamos absolutamente certos no tocante a Sêneca), temos duas possibilidades, com relação ao método filosófico empreendido por Sêneca. Ou o filósofo estaria de fato se contradizendo ao apelar a razões de outra ordem que não a lógica; ou a razão, em Sêneca, faria às vezes também de vontade, revelando assim um aspecto desejante. Em um sentido ou em outro, talvez Sêneca possa mesmo estar se distanciando um pouco da proposta formulada pelos antigos estoicos, como havia sugerido Cooper. A questão é demasiado problemática e não temos a pretensão de oferecer respostas que sejam capazes de preencher suas lacunas completamente. Neste caso, preferimos deixá-la em aberto, lembrando, em todo caso, que a hipótese de o conceito de razão aí envolvido ser mais amplo e mais complexo do que pode parecer à primeira vista pode realmente fazer algum sentido. Basta lembrar, para isso, que Sêneca aproxima razão e vontade algumas vezes em suas epístolas ${ }^{32}$.

\section{O paradoxo das adversidades}

Cumpre aqui, para que possamos finalizar o presente artigo, colocar duas questões: uma vez aceite a formulação estoica a propósito de uma escala de valores que contenha, de fato, uma categoria dedicada aos indiferentes, como poderíamos, portanto, pensar a relação do ser humano frente a cada uma das coisas e eventos que constituem o mundo que se encontra ao seu redor? Ora, pois se tudo o que não depende de nós é, de fato, indiferente, onde estaria o mérito em superar eventos, como, por exemplo, a morte e o sofrimento inerentes à própria vida humana? Pois não seria um dos mais cé-

sivamente técnicos, não poderia constituir tarefa de valor. O que não implica que ele esteja relegando ao desprezo a argumentação tradicional filosófica, de caráter simples e direto. Vale ainda lembrar que a cavillatio, termo ao qual nosso autor recorre quando geralmente expõe suas críticas, possui por si só um caráter pejorativo, de troça e ironia, caracterizando o sofisma, por oposição ao raciocínio justo, ou filosofema. Conferir as seguintes passagens, bastante importantes no que se refere a esta interessante problemática: Ep. LXXXII, 8, 1920; CXI, 1-2. Conferir ainda a nota de número 4, elaborada por Segurado e Campos, à Ep. CXI, na edição de sua tradução das Epistulae. In: SÉNECA. Cartas a Lucílio. Trad. J. A. Segurado e Campos. Lisboa: Fundação Calouste Gulbenkian, 2009.

32 Veja-se a este respeito, sobretudo, Ep. LXXI, 27. 
lebres traços ligados à ideia do sábio estoico aquele que salienta sua força e capacidade de suportar as adversidades?

Sêneca explicita, quando em vez, sua opinião acerca das adversidades. Ora, ele dedica toda uma de suas epístolas para argumentar que todo bem é desejável e que, mesmo neste caso, inclusive o sofrimento decorrente da tortura, tomado como consequência da coragem $\square$ que é uma virtude e, portanto, um bem $\square$ o seria (Ep. LXVI). A argumentação parece absurda, mas pode ser explicada pela delimitação do ato e do modo como o enfrentamos, conforme já explicitado anteriormente. É fácil perceber que o que caracteriza a virtude é a disposição com que procedemos a dadas ações, e não a própria ação em si. Assim, não há dúvidas de que, para nosso autor, há mérito em suportar adversidades. O que não implica que devamos inferir que haja, em sua filosofia moral, uma contradição na medida em que as adversidades constituiriam, por isso, um $\mathrm{mal}^{33}$.

O que é digno de nota, e que parece ter sido muito bem observado por $\mathrm{Motto}^{34}$, é a explícita preferência demonstrada por Sêneca com relação a uma vida atribulada, por oposição a um ócio tranquilo e despreocupado: "nada ter que te estimule, que te incite, cujo anúncio e conflito testem a firmeza de tua alma, mas no ócio inalterado jazer, isso não é tranquilidade, é preguiça" ${ }^{35}$. Ora, o que parece estar em jogo aqui, é que a vida feliz é em verdade determinada pela esfera moral - e compreender isso é questão de interpretação. Consequentemente, para Sêneca, perspectivas de fenômenos que poderiam parecer, num primeiro momento, aterradores, tais como no caso da morte e de adversidades em geral, poderiam se converter em circunstâncias não apenas aceitáveis, mas ainda louváveis, dependendo da dis-

\footnotetext{
${ }^{33}$ A este respeito já havíamos procurado explicitar acima que a doutrina conforme a qual tenderíamos a preferir, por natureza, a vida à morte, assentava-se na perspectiva de que aquela estaria em maior conformidade com a nossa natureza, em relação a esta última. Não sem razão, portanto, alguns indiferentes - como é o caso da própria morte - tendem a nos provocar mais temor do que outros. E seria justamente por conta de nossa dificuldade natural em lidar com tais situações ou circunstâncias que o ato de enfrentá-las parece constituir tarefa de tão elevado mérito.

${ }^{34}$ Motto observa que, para Sêneca, a "adversidade é preferível à boa fortuna nisso: a dificuldade literalmente força o ser humano a suportar, enquanto a prosperidade não". MOTTO, L. Seneca and the paradox of felicitas. In: Further essays on Seneca. Frankfurt; New York: Peter Lang, 2001, p. 45-53.

${ }^{35}$ Ep. LXVII, 14. Nihil habere, ad quod exciteris, ad quod te concites, cuius denuntiatione et incursu firmitatem animi tui temptes, sed in otio inconcusso iacere non est tranquillitas: malacia est.
} 
posição com que as enfrentemos. Em outras palavras, morte e sofrimentos de caráter diverso poderiam ser traduzidos em meios ou oportunidades de fortalecimento do ponto de vista moral.

Em conclusão, parece-nos que Sêneca, a seu modo, parece estar construindo uma ética centrada no vir fortis, ao enfatizar como figura emblemática de seu ideal ético a de um ser humano de caráter confiante e seguro, saudável e generoso para com tudo aquilo que constitui sua própria vida, na medida em que se mostra em harmonia com sua própria natureza e com aquela que o criou, forte e poderosa.

\section{Referências}

ARNIM, H. (2002). Stoici antichi, tutti i frammenti. Trad. Roberto Radice. Milano: Bompiani (=SVF).

BARNES, J. (1997)..Logic and the imperial Stoa. Leiden; New York; Köln: Brill.

BETANCUR-GOMEZ, J. C. (2012). Filosofía y ejercicio del alma en las Cartas a Lucilio de Séneca. Revista Pensamiento y Cultura, Vol. 15-2, p. 123-133.

BRIDOUX, A. (1966). Le stoicisme et son influence. Paris : J. Vrin.

BRUN, J. (1986). O estoicismo. Trad. João Amado. Lisboa: Edições 70.

COOPER, J. (2006). Seneca On Moral Theory and Moral Improvement. In: VOLK \& WILLIAMS. Seeing Seneca Whole: Perspectives on Philosophy, Poetry and Politics. Leiden: Brill, p. 43-55.

COOPER, J. M.; HUTCHINSON, D. (Eds.). (1997). Plato: Complete Works. Indianapolis: Hackett Publishing Company.

EPICURO. (2013). Máximas principais. Trad. João Quartim de Moraes. São Paulo: Loyola.

INWOOD, B. (Org.). (2006). Os estoicos. Trad. Raul Fiker. São Paulo: Odysseus Editora.

LONG, A. \& SEDLEY, D. (2001). Les philosophes hellénistiques. Trad. Jacques Brunschwig et Pierre Pellegrin. Paris: Flammarion, V.2 Les stoiciens. (=LS).

MOTTO, L. (2001).Further essays on Seneca. Frankfurt; New York: Peter Lang. 
SENECA. (1989). Ad Lucilium epistulae morales. 3 v. With English translation by Richard Gummere. Cambridge (UK): Harvard University Press.

SÉNECA. (2009). Cartas a Lucílio. Trad. J. A. Segurado e Campos. Lisboa: Fundação Calouste Gulbenkian.

SÉNÈQUE. (1947-1969). Lettres a Lucilius. Trad. Henri Noblot. Paris: Les Belles Lettres.

SENECA. (1993). Sobre a brevidade da vida. Trad. William Li, ed. bilíngue. São Paulo: Nova Alexandria. 